\title{
COLONIZACIÓN AGRÍCOLA Y DISTRIBUCIÓN DE LA RIQUEZA INMOBILIARIA EN LA PROVINCIA DE SANTA FE, ARGENTINA, 1864-1875
}

\author{
Juan Luis Martirén \\ Universidad de Buenos Aires, Buenos Aires, Argentina, <jlmartiren@hotmail.com>
}

\begin{abstract}
Resumen. El presente artículo busca medir la distribución de la riqueza inmobiliaria en las colonias agrícolas de la provincia de Santa Fe -Argentina- en las décadas de 1860 y 1870. A partir de registros de Contribución Directa - un impuesto provincial sobre la riqueza individual de cada contribuyente- correspondientes a los años fiscales de 1864, 1867, 1868 y 1875 (complementados con las manuscritas del Censo Nacional de Población de 1869), se busca analizar no sólo la evolución de la distribución espacial de la riqueza en las colonias primigenias -a partir de los casos de Esperanza y San Carlos-, sino también comparar esa variable con las colonias satélites que comienzan a surgir desde fines de la década de 1860, para mostrar así las particularidades y diferencias de este novedoso proceso de cambio productivo.
\end{abstract}

Palabras clave: colonización agrícola, distribución de la riqueza, inmigración.

Abstract. The paper seeks to measure wealth distribution in the agricultural colonies of Santa Fe Province, Argentina from the 1860s to the 1880s. Santa Fe province is located in the Pampean region, an area of fertile plains and the source of Argentina's agricultural and economic development in the nineteenth century. Using records from the contribución directa (a provincial tax on the individual wealth of each contributor) for fiscal years 1864, 1867, 1868 and 1875 (supplemented with records of the National Census of 1869), we analyze the evolution of the spatial distribution of wealth in the older colonies and compare that variable with the satellite colonies that began to appear in the late 1860 s. The goal is to show the unique patterns by which the colonization process led to changes in farm and land productivity.

Key words: agricultural colonization, wealth distribution, immigration.

Fecha de recepción: febrero de 2011. Fecha de aceptación: mayo de 2011

Am. Lat. Hist. Econ., año 19, núm. 2 (38), mayo-agosto, 2012, pp. 47-71 
$\mathrm{D}$ esde mediados del siglo XIX se puso en marcha en la provincia de Santa Fe un proceso de colonización agrícola con base en la instalación de inmigrantes europeos que modificaría sustancialmente su estructura productiva; en sólo 40 años pasó de ser una de las provincias más despobladas y menos productivas de la región pampeana argentina a una de las principales regiones productoras de trigo en el mundo. ${ }^{1}$ Esta emergencia de un sistema de producción alternativo al de la tradicional ganadería criolla, estuvo caracterizado en sus inicios por una pauta relativamente igualitaria de distribución de la riqueza inmobiliaria, ya que los agricultores establecidos en las primeras colonias comenzaron sus actividades con la misma cantidad de tierra, esto es, parcelas de 33 hectáreas. Además, se trataba en general de inmigrantes europeos que habían arribado al país con pocos recursos, sin mayores bienes de capital. Sin embargo, esa pauta igualitaria comenzaría a desdibujarse a medida que los colonos comenzaran a acumular riqueza, sobre todo a partir del importante crecimiento económico que en la zona de colonias produjo la guerra de $\mathrm{Pa}$ raguay en la segunda mitad de la década de 1860, ya que estas operaron como proveedores de cereales de los ejércitos en pugna.

Los procesos de modernización económica y productiva y sus efectos sobre la distribución de la riqueza que se genera a partir de los mismos han sido ampliamente analizados en el campo académico, siendo quizá Simon Kuznets uno de los autores más relevantes. Sus investigaciones buscaron explicar los patrones de distribución de la riqueza durante el desarrollo del proceso de industrialización británica, concluyendo que habría existido una tendencia a la desigualdad en los momentos iniciales de este ciclo, aunque luego esta tendencia se habría ido equilibrando e incluso disminuyendo. ${ }^{2}$ Entre amplias discusiones, la bibliografía académica más moderna ha indagado sobre los diversos factores que intervienen en los cambios en la distribución de la riqueza. Se ha propuesto, por un lado, si se trata sólo de una cuestión de generación de demanda y oferta de factores, esto es, cómo participan estos en los distintos procesos de crecimiento y paralelamente en que los mismos resulten en homogeneidad o heterogeneidad en la distribución de la riqueza. ${ }^{3}$ Y por otro, se ha hecho hincapié en el papel de otra variable fundamental, la institucionalidad y su influencia en el crecimiento económico y su distribución. ${ }^{4}$

\footnotetext{
${ }^{1}$ Véase, entre otros, Gallo, "Agricultural", 1970.

${ }^{2}$ Esta interpretación dio lugar a la famosa U invertida de Kuznets. La obra original en Kuznets, Modern, 1966. Si bien las ideas de Kuznets han sido muy discutidas, muchos autores han encontrado coincidencias en los patrones de desigualdad. La obra quizá más emblemática de esta corriente es Williamson y Lindert, American, 1980.

${ }^{3}$ Engerman y Socoloff, "Dotaciones", 1999.

${ }^{4}$ Por ejemplo, Acemoglu, Johnson y Robinson, "Institutions”, 2005.
} 
Ahora bien, ¿̇qué ocurre en el mundo rural, esto es, en sistemas productivos donde la tierra desempeñó un papel fundamental en la distribución de los factores? En el caso argentino, los estudios tradicionales habían destacado la existencia de una distribución fuertemente inequitativa de la riqueza, sustentada principalmente en la distribución desigual de la tierra. ${ }^{5}$ Sin embargo, nuevos estudios pusieron el foco de atención en la importancia del factor frontera y en la posibilidad de contar con una progresiva oferta de tierras. Se han matizado así dichas ideas, destacando el papel en ciertos casos "homogeneizador" de estas variables adicionales. ${ }^{6}$

En este contexto resulta particularmente interesante analizar el caso de las colonias agrícolas santafesinas, que incorporaron pautas de producción más intensivas $\mathrm{y}$, por ende, incrementaron en gran medida la productividad de la tierra. La acertada combinación de factores -introduciendo en forma planificada núcleos con alta dotación de mano de obra en una economía donde el valor del trabajo era muy alto en razón de la escasez poblacional, y donde inversamente la tierra era abundante- produjo a partir de cierto momento una rápida prosperidad que debió reflejarse en la acumulación de riqueza individual. En este trabajo buscamos acercarnos al perfil de riqueza de los actores en un contexto en el que todas las familias recibieron el mismo capital inicial, con el fin de evaluar quiénes recogieron en mayor medida los frutos del valor agregado generado. Al mismo tiempo, el trabajo pretenderá medir la distribución y composición de la riqueza inmobiliaria. Puesto que en torno a la misma surgirá un mercado de tierras y aparecerán grandes empresarios de colonización, una de las preguntas a responder es justamente en qué medida ese auge inmobiliario constituyó para otros actores menos visibles, como los mismos colonos, una oportunidad para acumular riqueza. El ámbito del estudio es el área de las colonias agrícolas del centro oeste santafesino durante las décadas de 1860 y 1870, esto es, el núcleo inicial de la colonización en esa provincia. Las colonias primigenias de Esperanza, San Carlos y San Gerónimo, más las colonias satélites que surgieron al calor de la expansión de estas (San Agustín, Las Tunas, Franck, Cavour, Humboldt y Santa María) servirán en consecuencia como punto de partida para el análisis, que quedará circunscrito a la disponibilidad de las fuentes relativas a cada colonia. Para la década de 1860, entonces, se analizará la distribución de la riqueza in-

\footnotetext{
${ }^{5}$ Algunos estudios clásicos de esta corriente son Ortiz, Historia, 1955; Oddone, Burguesía, 1967, y Cárcano, Evolución, 1972.

${ }^{6}$ El trabajo pionero es el de Cortés, Progreso, 1979; véase además, entre otros, Gelman y Santilli, Rivadavia, 2006. Existen también investigaciones de Luis Bértola sobre sociedades de nuevo asentamiento, entre las cuales se incluye el caso argentino, véanse Bértola, "Cincuenta", 2005, y Ensayos, 2000. Véase también Williamson, "Real”, 1999.
} 
mobiliaria en las colonias de Esperanza y San Carlos, mientras que para la década de 1870, se tomará en cuenta la totalidad de las colonias.

Las fuentes utilizadas para ese propósito son los registros de contribución directa elaborados para cada colonia. ${ }^{7}$ Para la colonia Esperanza se utilizarán los registros correspondientes a los años fiscales de 1864, 1867 y 1875; para la colonia San Carlos los registros de 1868 y 1875 y para las demás colonias sólo contamos con los registros de $1875 .^{8}$ Todos los casos son complementados, asimismo, con las cédulas manuscritas del Censo Nacional de Población de 1869 y con los protocolos notariales elaborados por los juzgados de paz o eventualmente por los escribanos públicos de cada colonia. ${ }^{9}$ Es importante remarcar, asimismo, que esta complementación ha permitido chequear tanto la confiabilidad de los montos declarados así como también la universalidad de la fuente. Afortunadamente, pese a que la Ley de Contribución Directa eximía del pago a aquellos contribuyentes que contaban con capitales menores a 500 pesos fuertes, en los registros analizados se ha dado cuenta de la totalidad de los jefes de familia poseedores de bienes en cada colonia. ${ }^{10}$ Por lo demás, a partir de un relevamiento completo de las operaciones de compraventa en todas las colonias durante el periodo analizado, encontramos correspondencias entre los valores declarados en los registros y el valor de mercado de estos bienes, lo que nos permite desestimar el riesgo de subvaluación en dicha fuente. ${ }^{11}$

${ }^{7} \mathrm{El}$ impuesto de contribución directa era un gravamen provincial sobre la riqueza individual de cada contribuyente, resultando sus registros una fuente de gran interés para el análisis de la riqueza y su distribución. Una explicación detallada puede encontrarse en Gelman y Santilli, Rivadavia, 2006.

${ }^{8}$ Los registros de contribución directa de Esperanza correspondientes a los años fiscales de 1864 y 1867 se encuentran en el Archivo General de la Provincia de Santa Fe (en adelante AGPSF), Contaduría, t. 117, 1864, leg. 28, y t. 127, 1867, leg. 1. Los registros de contribución directa de San Carlos, correspondientes al año fiscal de 1868, en AGPSF, Contaduría, t. sin núm., archivo, 1870, leg. 40. Los registros de contribución directa correspondientes a 1875 para todas las colonias, en AGPSF, Contaduría, t. 117, expedientes archivados, 1875, leg. 44. localidades.

${ }^{9}$ Los protocolos notariales registraban las transacciones inmobiliarias de cada una de esas

${ }^{10} \mathrm{El}$ peso fuerte correspondía al antiguo peso de plata español, con el debasement establecido en época revolucionaria (que hizo equivaler 17 de los mismos a una onza de oro, cuando anteriormente eran sólo 16). En nuestra época y lugar, era fundamentalmente una moneda de cuenta, puesto que en la circulación se empleaba el peso boliviano, metálico pero de menor ley y valor variable.

${ }^{11}$ Vale destacar que los distintos gobiernos provinciales también estaban preocupados por la subvaluación en los registros de contribución directa. Por ejemplo, si bien no es analizado en este trabajo, el registro de la colonia Esperanza correspondiente a 1866 fue observado por las autoridades puesto que las valuaciones se habían realizado en pesos bolivianos y no en pesos fuertes, como indicaba la ley, por lo que debió reconfeccionarse; ello indica que aquellas estaban atentas a posibles ocultamientos. 
El CENTRO OESTE SANTAFESINO EN LAS DÉCADAS DE 1860 Y 1870

Hacia mediados de la década de 1850 , la provincia de Santa Fe no tenía poblada más que una pequeña parte de su actual territorio, con algo menos de 50000 habitantes. Azotada desde la década de 1820 por constantes guerras civiles, su plantel ganadero había tenido importantes mermas que afectaron directamente la producción y las finanzas provinciales. ${ }^{12}$ Recién promediado el siglo comenzaría a avizorarse la preocupación oficial por fomentar el desarrollo de la agricultura. ${ }^{13}$ Siguiendo los pasos de las experiencias de colonización iniciadas en el sur brasileño unas décadas antes, se buscaba así sentar las bases de un nuevo sistema productivo, que combinara mano de obra y capital extranjeros con el potencial que ofrecía la enorme disponibilidad de tierras que tenía la provincia. En ese contexto se puso en marcha un proceso de colonización agrícola que terminaría por modificar sustancialmente la estructura socioeconómica y productiva provincial (véase mapa 1). ${ }^{14}$

En términos generales, este fenómeno implicó la creación de núcleos de producción agrícola -denominados colonias- sobre tierras públicas o privadas, delineadas previamente en pequeños minifundios (que generalmente tenían entre 30 y 40 hectáreas), y poblados en la mayoría de los casos por extranjeros, particularmente europeos. Los primeros proyectos de colonización se iniciaron en el segundo lustro de la década de 1850 con el establecimiento de inmigrantes suizos, alemanes y franceses en tierras cercanas a la ciudad de Santa Fe, capital de la provincia.

Si bien el proceso se extendió sobre diversas regiones de la provincia, la región centro oeste ya desde los inicios fue la más colonizada, pudiéndose identificar básicamente dos etapas durante el periodo analizado. La etapa inicial implicó el establecimiento de Esperanza, San Carlos y San Gerónimo, que fueron las tres primeras colonias fundadas en territorio santafesino. Luego de difíciles años iniciales, estos emprendimientos comenzarían a afianzarse desde inicios de la década de 1860 y a despegar con la demanda desatada por los ejércitos que combatieron en la guerra de Paraguay durante el segundo lustro de la misma. ${ }^{15}$ Ello abriría un nuevo abanico de posibilidades tanto para los colonos ya establecidos, cuanto

${ }^{12}$ Véanse Gallo, "Santa”, 1965, y Frid, "Preludio", 2007.

${ }^{13}$ Djenderedjian, "Colonización", 2008, p. 129.

${ }^{14}$ Gallo, "Agricultural", 1970, y Bonaudo y Sonzogni, "Cuando", 2000.

${ }^{15}$ La llamada guerra de Paraguay fue un episodio bélico acontecido entre 1865 y 1870, en el cual una alianza formada por Brasil, Uruguay y Argentina se enfrentó militarmente contra Paraguay. Puesto que las colonias estaban ubicadas a pocos kilómetros del puerto de la ciudad de Santa Fe, punto de paso en el tráfico fluvial hacia Paraguay, esto les permitió consolidarse como proveedoras de los ejércitos aliados. 
MAPA 1. LA REGIÓN PAMPEANA ARGENTINA

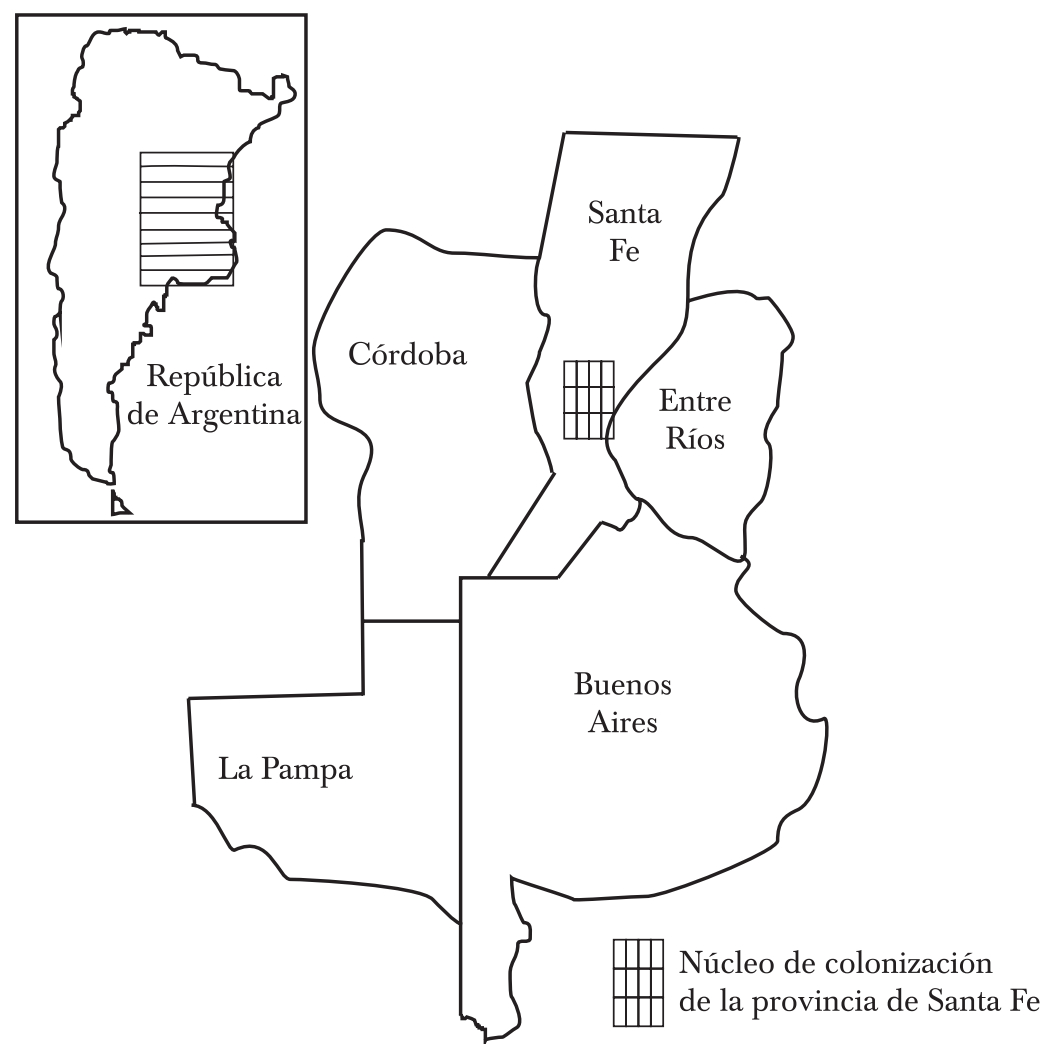

Fuente: elaboración propia con base en Randle, Atlas, 1981.

para los que formaron parte de nuevas corrientes inmigratorias que arribaron entre 1868 y 1870, lo cual permitiría la formación de otro núcleo de colonización en tierras ubicadas al norte de la ciudad capital y también en torno a las tres primeras, expandiendo hacia el oeste la línea de frontera. De este modo, colonos de Esperanza volcaron sus excedentes en la compra de concesiones en Humboldt, Cavour, algunos en Franck y, posteriormente, en Santa María; colonos de San Carlos hicieron lo propio en San Agustín, Franck y Las Tunas, y colonos de San Gerónimo puntualmente en Las Tunas (véase mapa 2).

La segunda etapa, iniciada en pleno apogeo del boom paraguayo y amortiguada circunstancialmente por el impacto de la crisis económica 

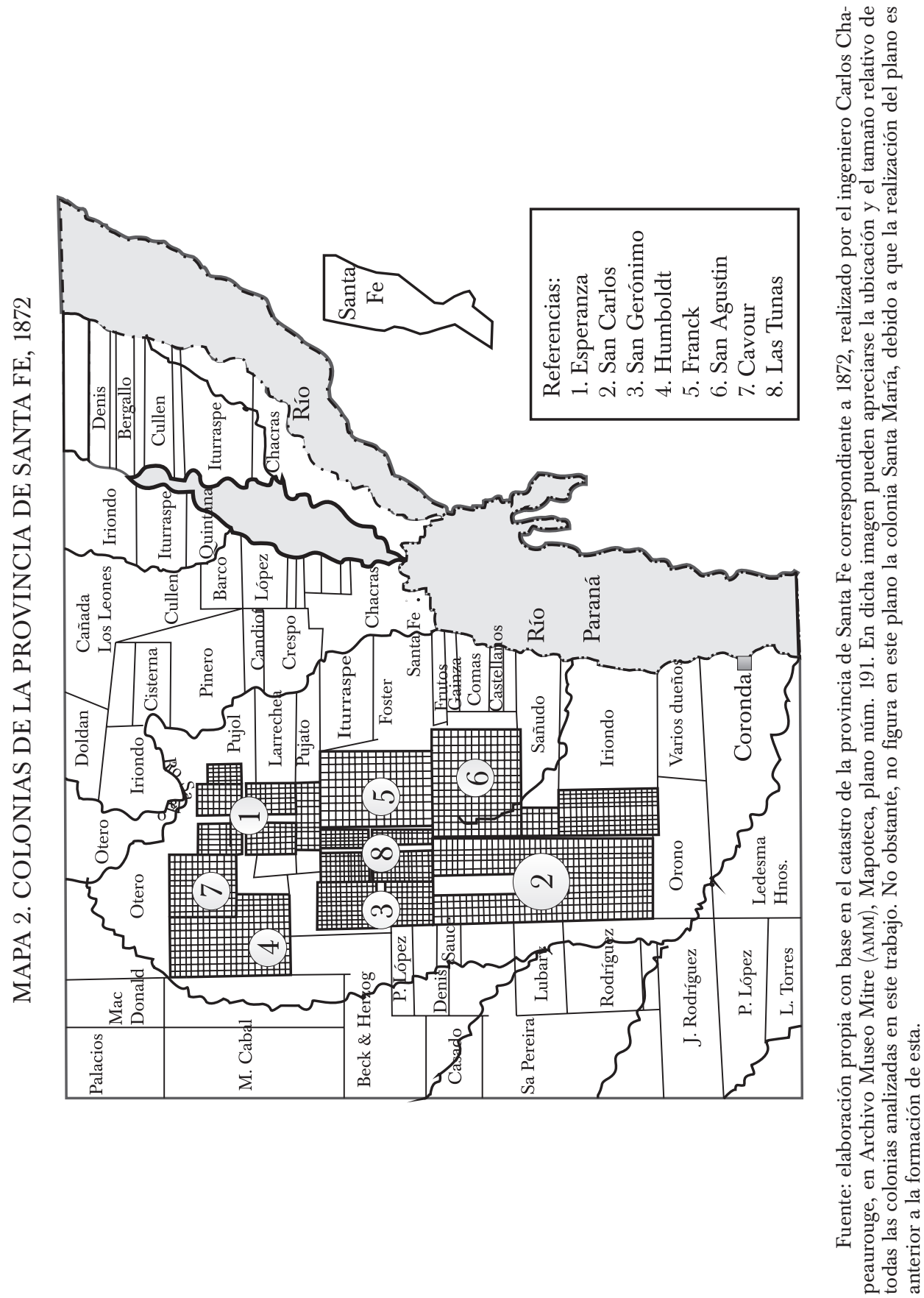
de 1873, sería el preludio de la espectacular expansión productiva y demográfica que tendría el proceso a partir de la década de 1880. En algo más de dos décadas de colonización agrícola, la fisonomía espacial del centro oeste había sufrido importantes transformaciones; de ser un territorio prácticamente despoblado y escasamente productivo, había pasado a tener en 1875 nueve colonias, con alrededor de 7000 habitantes y algo más de 30000 hectáreas sembradas. ${ }^{16}$

\section{ACUMULACIÓN Y DISTRIBUCIÓN DE LA RIQUEZA INMOBILIARIA EN LAS COLONIAS}

El mundo rural pampeano en el siglo XIX se caracterizó por los índices generales relativamente altos de desigualdad en la distribución de la riqueza, más allá de fuertes variaciones regionales y de amplias capas medias de propietarios. ${ }^{17} \mathrm{El}$ proceso de colonización apareció en ese escenario como un esquema radicalmente nuevo: además de constituir tenencias perfectamente iguales, se impuso como un nuevo sistema de propiedad que no sólo estableció la necesidad de contar con un catastro general de la región, sino también con una burocracia especializada en el registro de las operaciones inmobiliarias. La condición de propietarios perfectos de una superficie determinada y delimitada pasó a ser una clave fundamental, porque hasta ese momento el dominio pleno de la tierra sólo existía en los papeles para una pequeña elite de estancieros en general de residencia urbana. ${ }^{18}$ Es importante indagar entonces sobre una serie de interrogantes al respecto: ¿cómo evolucionó la distribución de la riqueza inmobiliaria en un espacio productivo cimentado en sus inicios sobre pautas igualitarias en el acceso a la tierra?, ¿hasta qué punto este nuevo componente institucional fue contaminado por el contexto y en qué medida ello afectó el esquema de distribución de la riqueza?, ćcómo impactó en ese esquema el proceso de acumulación obtenida por esos actores?, ¿cómo operó el factor frontera en un espacio productivo que absorbía constantemente nuevos flujos de población?

${ }^{16}$ Datos extraídos del anexo del Informe del Inspector de Colonias Provincial de 1874. Véase Coelho, Memoria, 1875.

${ }^{17}$ Gelman y Santilli, Rivadavia, 2006, y "Creciente", 2009, y Djenderedjian y Schmit, "Sombras", 2005.

${ }^{18}$ Lo normal era que los pequeños productores del mundo rural criollo ocuparan o arrendaran mediante contrato verbal las tierras públicas o de las grandes estancias, no contando con títulos formales. A tal punto el nuevo sistema de propiedad perfecta de las colonias fue diferente, que las primeras actas de transferencia de dominio están redactadas en alemán y francés, y aparecen frecuentemente unidades de medida de esos mismos países (léase, el pose o el juckart), marcando así la extemporaneidad del sistema. 


\section{Viejas y nuevas colonias: diferencias y continuidades en el seno de un mismo proceso productivo}

Las colonias primigenias fundadas en la década de 1850 tuvieron ciertas particularidades que habrían de diferenciarlas de las que se formarían posteriormente, ya que no sólo fueron establecidas a partir de una transformación consciente de las bases productivas, sino que también fueron previas al surgimiento de un mercado de tierras en el centro oeste provincial. En este sentido, vale la pena comparar, por un lado, la evolución de la distribución de la riqueza en San Carlos y Esperanza ${ }^{19}$ en las décadas de 1860 y 1870, para luego confrontar esos datos con los elaborados para la totalidad de las colonias correspondientes al año fiscal de 1875.

La década de 1860 resulta, en consecuencia, una etapa verdaderamente útil para medir la evolución de la desigualdad, ya que los efectos económicos producidos por la guerra de Paraguay operarían como efecto bisagra en el derrotero productivo de la zona. El cuadro 1 comparativo de los dos registros de contribución directa de Esperanza y San Carlos correspondientes a las décadas de 1860 y 1870 permite una primera impresión sobre la distribución de la riqueza en las colonias, ya que ambos abarcan el universo total de propietarios de ambos espacios productivos.

En ese aspecto, la proporción de contribuyentes en Esperanza estimada sobre el total de unidades familiares sería de $86 \%$ en el registro de 1864 (304 contribuyentes para 355 familias) y de 87\% en el registro de 1867 (268 contribuyentes para 305 familias), mientras que en San Carlos alcanzaría $55 \%$ (141 contribuyentes para 255 familias). ${ }^{20}$

${ }^{19} \mathrm{Si}$ bien San Gerónimo forma parte de las colonias primigenias, lamentablemente no contamos con registros de contribución directa para la década de 1860, lo cual no permite elaborar una comparación para esta etapa.

${ }^{20}$ Las fuentes utilizadas para calcular la cantidad de familias según el año fueron: para Esperanza en 1864 se cruzó la información proveniente de un cuadro estadístico inédito correspondiente a la colonia para 1865 con los datos del Censo Nacional de Población de 1869. Para el registro de contribución directa de 1867 se tomaron los datos del censo de población y datos estadísticos editados en una publicación oficial sobre las colonias ese año. Para San Carlos en 1868 se tomaron los datos del Censo Nacional de Población de 1869, puesto que había una diferencia de sólo cinco meses con la elaboración del registro de contribución directa. Para el registro de contribución directa de 1875, en ambos casos se confrontaron datos del censo de colonias de 1872, que especificaba la cantidad de familias por colonia, con el total de población que en ambas estimaba el inspector de colonias de 1874. De este modo, se dividió el total de la población de 1874 por el número de integrantes promedio por núcleo familiar arrojado por el censo de 1872 . Documentos disponibles en AGPSF, Archivo de gobierno, t. 30, 1867, fs. 226 y ss., y fichas manuscritas del Censo Nacional de Población, en Archivo General de la Nación (AGN), legs. 385-387; también Gobierno Nacional de Argentina, Argentinische, 1869; Wilcken, Colonias, 1873, y Coelho, Memoria, 1875 . 


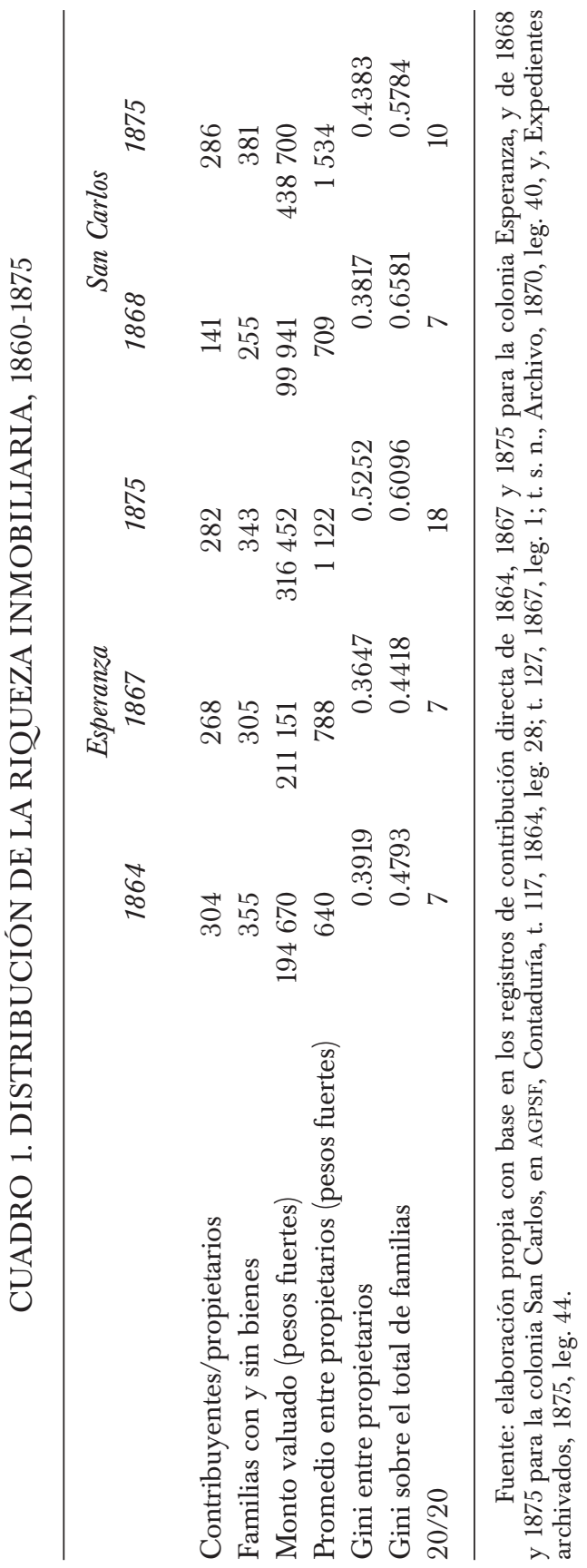


Respecto a las mediciones, es conveniente destacar las particularidades que arroja el registro de contribución directa de Esperanza de 1864, puesto que resulta el primer diagnóstico de la evolución de la desigualdad en la distribución de la riqueza inmobiliaria, ocho años después de su fundación. Teniendo en cuenta sólo el universo de propietarios, la primera aproximación permite afirmar que la distribución de la riqueza en Esperanza era mucho más homogénea que en otras zonas del mundo rural pampeano. ${ }^{21}$ Según los cálculos realizados, el índice Gini entre propietarios de la colonia era de 0.3919 y el $20 \%$ más rico tenía en promedio siete veces más capital que el $20 \%$ más pobre. Esta cuestión variaba un poco al tomar en cuenta en el análisis el universo total de potenciales tenedores de riqueza, esto es, incluyendo a las familias sin bienes. Así, el índice Gini aumentaba a 0.4793 , un promedio igualmente bajo en comparación con la economía criolla, pero de todos modos llamativo dado el corto periodo transcurrido desde la formación de la colonia. ${ }^{22}$ En ese sentido, para un primer diagnóstico debe advertirse que paradójicamente el crecimiento de la desigualdad fue muy alto en esos primeros años, puesto que se pasó de un punto de partida virtualmente igualitario a una situación intermedia entre la perfecta igualdad y la total desigualdad. De todos modos, esa circunstancia se relativizará al continuar el análisis en el tiempo y a su vez comparar con otros espacios productivos similares y cercanos.

Es interesante entonces contrastar la distribución de la riqueza inmobiliaria resultante del registro de 1864 con el de 1867, para medir en el corto plazo cómo fue la evolución de esa tendencia a la desigualdad. En este sentido debe remarcarse la caída en la cantidad de contribuyentes y de población que hubo en la colonia en esos años. Dos razones permiten explicar este fenómeno; por un lado, la limitada configuración espacial de la colonia generaba problemas de productividad, ya que el tamaño de las concesiones de terreno comenzó a volverse ineficiente, no sólo por cuestiones edafológicas (los colonos no tenían posibilidad de dejar descansar la tierra en barbechos de al menos un año, para no perder fertilidad, puesto

\footnotetext{
${ }^{21}$ Varios trabajos demuestran estas afirmaciones: en 1862-1863, el universo de propietarios del distrito rural de Paraná, provincia de Entre Ríos, tenía un Gini de 0.788 , véase Djenderedjian y Schmit, "Sombras", 2005; en la campaña bonaerense en 1839 el promedio del Gini entre propietarios era de 0.66 y la diferencia en el índice $20 / 20$ era de 69 , mientras que para 1855 , sólo midiendo la propiedad inmueble, el Gini era de 0.65 y el 20/20 muy similar al anterior. Ahora bien, teniendo en cuenta el total de la población, el Gini en 1839 pasaba a ser de 0.88 y en 1855 de 0.91, una proporción mucho más alta, véase Gelman y Santilli, "Creciente", 2009. Una comparación de las colonias santafesinas y un área criolla entrerriana en Djenderedjian y Martirén, "Economía", 2009.

${ }^{22}$ Denominaremos aquí "economía criolla" a la tradicional producción agraria en pequeña y mediana escala del área, centrada en la ganadería vacuna u ovina, con aislados y limitados espacios agrícolas, uso muy extensivo de la tierra y basada principalmente en mano de obra familiar.
} 
que los lotes se volvieron muy pequeños para las pautas productivas que resultaron más útiles, y no había campos libres cercanos), sino también demográficas. Esta razón llevó a varios colonos de Esperanza a buscar nuevas extensiones de tierra en áreas más alejadas, a precios más bajos y funcionales a su propia lógica productiva. Este fenómeno de disminución de la población y de propietarios en Esperanza no sólo se reflejó en la distribución, sino también en la acumulación de la riqueza, que tuvo una tendencia alcista. Es probable que esas unidades hayan pasado a formar parte del capital de más de un colono, es decir, algunas tenencias individuales se parcelaron en más de una. ${ }^{23} \mathrm{~A}$ esto se suman los efectos del auge paraguayo que impactó en el precio de la tierra agrícola, incluso quizá con más intensidad en las zonas marginales, lo cual explicaría tanto el aumento del capital inmobiliario como la disminución de la desigualdad en ese registro. En este sentido, mientras la riqueza inmobiliaria total de la colonia se incrementó $8.5 \%$, la evolución de la media por contribuyente tuvo un incremento mucho más marcado, superior a 23\%, pasando de 640 en 1864 a 788 pesos fuertes en 1867 .

A diferencia de Esperanza, San Carlos actuó como un verdadero polo de atracción para la población en la segunda mitad de la década de 1860, verificándose un importante incremento del índice Gini entre el universo de propietarios y el cálculo con el total de las familias. Una mejor planificación en el establecimiento de la colonia -a partir de la logística llevada a cabo por la empresa colonizadora que la fundó, que transformó a San Carlos en un dinámico e innovador centro de producción agrícola- fue quizá la única diferencia de consideración entre ambas colonias, que se explica en consecuencia por la gran afluencia de población que tuvo la colonia entre 1866 y $1870 .^{24}$

Ello permite pensar que el factor frontera desempeñó un papel fundamental no sólo en la configuración productiva de la colonia (al parecer más eficiente que en el caso de Esperanza), sino también en dicho exitoso proceso de absorción de nueva población. Así la ampliación de esos límites permitió el acceso a tierras más baratas y a una distancia similar a la que ya tenían en la antigua colonia respecto a los mercados de abasto y realización de excedentes, presionando hacia posibles subas en el precio de las tierras ya ocupadas.

Sin embargo, los cálculos de distribución de riqueza inmobiliaria realizados sobre los registros de contribución directa de 1875 parecen marcar a

${ }^{23}$ Un análisis sobre la parcelización de las concesiones de tierra en Esperanza en Martirén, "Colonias", 2010.

${ }^{24}$ Según estadísticas de Carlos Beck Bernard, San Carlos duplicó su población entre 1867 y 1870, pasando de tener 955 habitantes en 1867 a 2045 tres años más tarde. Beck, République, 1872, p. 140 . 
priori un escenario completamente diferente. La cuestión más importante es el aumento de la desigualdad que registraron ambas, aunque marcadamente mayor en Esperanza. El índice Gini entre propietarios muestra una suba destacable en Esperanza y otra sensiblemente menor en San Carlos, que se refleja también en el índice 20/20, donde el sector más rico en Esperanza pasó a tener 18 veces más que el grupo más pobre, mientras que en San Carlos esa diferencia sólo se multiplicó por diez. ${ }^{25}$

Tan sólo teniendo en cuenta que si se comparan los registros de ambas décadas, San Carlos aumentó su capital en inmuebles en 338\% y Esperanza en $116 \%$, parece lógico pensar que esa fenomenal creación de riqueza hubo de tener impacto considerable en su distribución. ${ }^{26} \mathrm{El}$ crecimiento de las medias por su parte se correspondió con estos cambios en el monto de la riqueza total, registrándose un aumento de $42 \%$ en Esperaza respecto a la media de 1867 y un aumento de más del doble en San Carlos respecto a 1868.

Es interesante remarcar también el mayor promedio de riqueza existente en San Carlos, que se corresponde con una distribución algo más equitativa y a su vez con las ventajas relativas sobre Esperanza que ya remarcamos antes. Esto es, la acumulación de la riqueza inmobiliaria se dio básicamente a partir de la expansión de sus fronteras de producción agrícola, lo cual generó que una importante masa de agricultores conformara la principal base de contribuyentes. En fin, en lo que respecta al menos a la distribución de la riqueza inmobiliaria, parece quedar claro que el aumento de la desigualdad en las colonias fue bastante importante, aunque quizá esperable a partir de las grandes transformaciones de ambos espacios, que se dieron por razones tanto estructurales como coyunturales. Por un lado, con mayores dimensiones en Esperanza, ambas colonias ya habían desarrollado su respectivo centro urbano, lo cual no sólo impactó en la cantidad de contribuyentes -sobre todo porque el incremento más fuerte se dio en los deciles más bajos-, sino también en los montos de capital de los sectores más altos. Por otro lado, el corrimiento hacia el oeste de la línea de fronteras implicó el surgimiento de las mencionadas colonias satélites, en las cuales se habían afianzado sistemas de venta de tierras con hipoteca, que permitió un acceso a la propiedad en forma relativamente fácil para inmigrantes con bajos recursos. Posiblemente esto haya actuado

${ }^{25}$ Por su parte, la disminución del Gini calculado sobre el total de las familias en San Carlos para 1875 parece tener una explicación coyuntural: el registro de 1868 coincidió con una importante llegada de inmigrantes que fueron censados (de ahí el alto Gini sobre el total de familias en el registro de ese año), y que seguramente para 1875 ya se habían convertido en propietarios.

${ }^{26}$ De acuerdo con el registro de contribución directa de 1868 , los inmuebles existentes en San Carlos estaban valuados en 99941 pesos fuertes, mientras que en 1875 habían aumentado a 438700 pesos fuertes. En el caso de Esperanza, el registro de 1867 valúa el rubro de inmuebles en la suma de 211151 pesos fuertes, mientras que en el de 1875 ese rubro asciende a 316452 pesos fuertes 
como factor de concentración de la riqueza en San Carlos y Esperanza, ya que como se verá más adelante, los hijos de muchos propietarios o integrantes de los sectores más bajos parecen haber optado por ese sistema, dejando por ende de ser un componente de la demanda en las colonias antiguas. Por último, esa expansión de la frontera implicó un fuerte salto en la producción de cereales, que se acompañó del crecimiento de la industria molinera y un incremento de los establecimientos comerciales, fenómeno que tendió a concentrar importantes inversiones de capital.

Estas razones parecen reflejarse también en los indicadores que arroja el cuadro 2, que toma en cuenta la distribución del ingreso en las nuevas colonias satélites y asimismo en el universo completo de colonias del centro oeste, permitiendo de este modo ampliar la noción del mapa de la distribución entre colonias viejas y nuevas.

Si bien el ordenamiento de las colonias en el cuadro 2 se realizó a partir de la cantidad de contribuyentes por colonia, la explicación de sus variaciones -salvo en San Gerónimo- tiene raíces en Esperanza y San Carlos. En primer lugar, es de destacar que el Gini general de todas las colonias es sensiblemente más alto que el resultante en cada una de las colonias nuevas. Esto ocurre porque allí están considerados los capitales de los propietarios de Esperanza y San Carlos que compraron en esas colonias nuevas. Es decir, por una coyuntura particular esas dos colonias antiguas generaron demandas insatisfechas de tierras durante más de una década. Y sólo con las fundaciones de finales de la década de 1860 apareció una oferta jurídicamente ordenada y consistente al respecto. Ello generó un vuelco de capital por parte de quienes habían logrado acumular fondos y por ende un aumento en la desigualdad si se considera el total de las colonias. ${ }^{27}$ En cambio, en los índices particulares de cada una de las colonias nuevas, sólo están considerados los propietarios que residían en las mismas, quienes difícilmente contaban con un capital comparable a las de estas dos.

El análisis de la distribución de la riqueza inmobiliaria en las colonias satélites resulta útil entonces no sólo para conocer la evolución de la acumulación, sino también para ver en perspectiva su comportamiento en una coyuntura determinada por el libre juego de la oferta y la demanda en un mercado de tierras ya consolidado. En este sentido, la distribución de la riqueza inmobiliaria medida a través del índice Gini o del indicador 20/20 tiene patrones relativamente similares en todas. Ello parece ser así porque la principal masa de propietarios de estas colonias era de agricul-

\footnotetext{
${ }^{27}$ Sin duda en varios casos esas parcelas estaban destinadas para los hijos de los compradores o para parientes que venían del extranjero, lo que a la larga, al independizarse los mismos, dejaría de impactar en el índice de Gini. Wilcken, Colonias, 1873.
} 


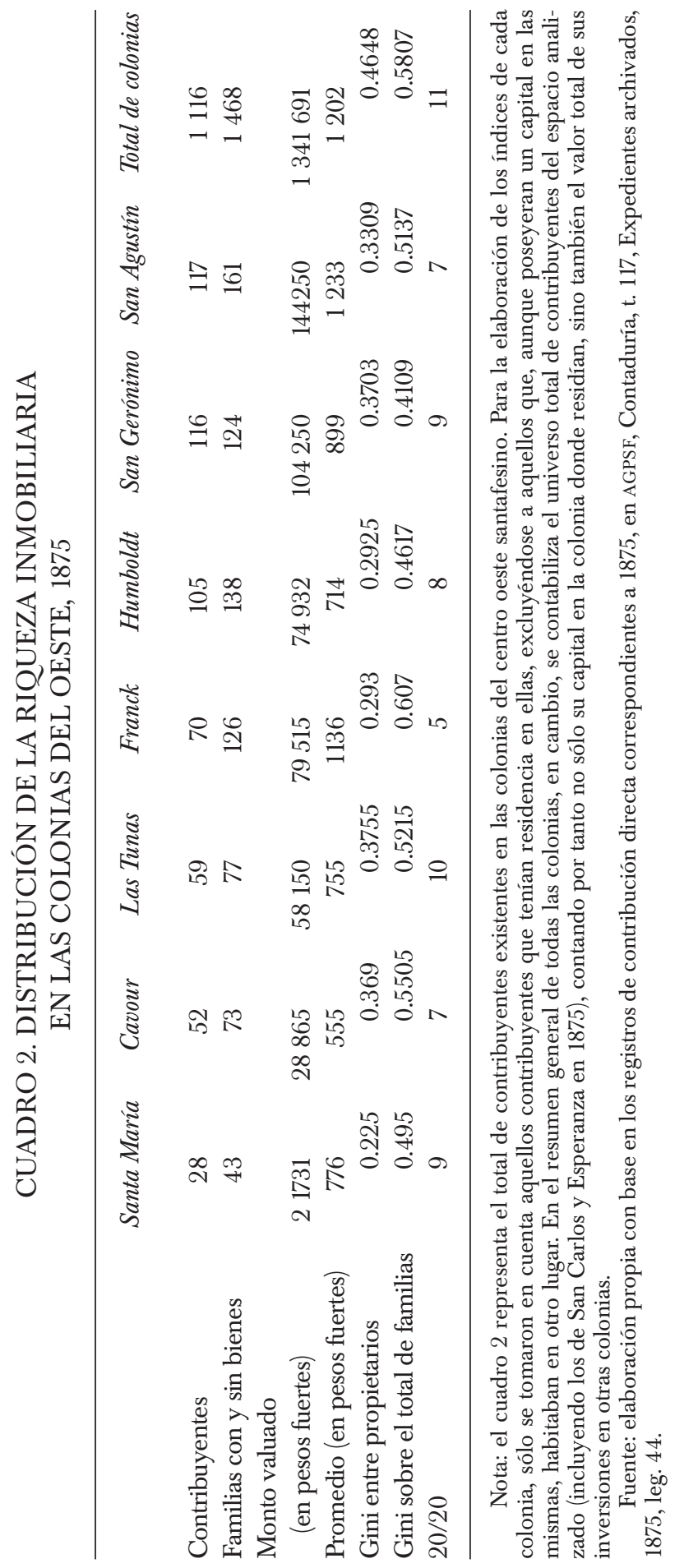


tores y, siendo que el promedio de tenencia de la tierra para cada propietario oscilaba entre dos y cuatro concesiones (salvo algunas excepciones), la distribución de la riqueza era relativamente pareja. Ahora bien, vale la pena destacar las diferencias en el nivel de acumulación, cuya explicación parece estar en la disposición geográfica y productiva de las mismas. De este modo, es notable la diferencia existente en cuanto al capital promedio en Franck y San Agustín respecto a las demás. Ello se debió a que estas dos colonias fueron una "extensión" de la pauta productiva de San Carlos, puesto que buena parte de los propietarios de las mismas fueron colonos sancarlinos que volcaron el excedente de su riqueza en inversiones de tierras en estas colonias vecinas. Ambas fueron pobladas a inicios de la década de 1870 en una coyuntura determinada por la oferta conveniente de tierra en colonias nuevas y el final del auge paraguayo, que acotó la realización mercantil de los cultivos, empujando así la inversión hacia la tierra antes que a una ampliación del parque productivo existente. Para 1875, estas inversiones habían comenzado a madurar, generando una valorización mayor de las parcelas por el capital realizado en mejoras. Es así que el promedio de capital por contribuyente en ambas colonias es considerablemente más alto que en las demás y bastante próximo al de San Carlos.

Los propietarios de Humboldt, Santa María y Cavour, por su parte, eran mayormente colonos agricultores de Esperanza, que buscaron también expandir sus inversiones hacia tierras más baratas debido a las limitaciones de esta colonia, pero contaban con menos capital y la misma delimitación de estas colonias imponía restricciones a la cantidad de tierra disponible. Si bien se advierte una relativa acumulación de riqueza, estas colonias satélites de Esperanza no acumularon tanto como sus vecinas atadas a la pauta productiva de San Carlos. Las Tunas, por su parte, es un caso diferente, donde se combinaron inversores de San Carlos, San Gerónimo y Esperanza.

Por último, vale explicar el caso de San Gerónimo que, como se dijo antes, forma parte de las colonias primigenias, aunque con matices bien distintos. La inexistencia de registros de contribución directa para la década de 1860 no permite realizar una comparación más amplia, aunque su configuración productiva y el patrón étnico característico de estructura demográfica la diferenciaron de las demás. Ello explica en gran medida la baja distancia entre familias propietarias y sin bienes, ya que, desde sus inicios, la colonia sólo acogió a las familias que arribaron por el accionar del líder valesano que se encargó de su reclutamiento. ${ }^{28}$

\footnotetext{
${ }^{28}$ La colonia San Gerónimo si bien nació de una iniciativa particular de un hacendado santafesino, se desarrolló gracias al accionar de un líder étnico, Lorenz Bodenmann, quien a partir de redes de relación personal en Valais, Suiza, promovió la instalación de casi 150 familias en cuatro viajes a Europa entre 1858 y 1865.
} 
¿Agricultores, comerciantes o industriales?

Los actores principales del proceso de acumulación de riqueza inmobiliaria

Si bien determinados índices de distribución y algunas impresiones basadas en fuentes cualitativas permiten inferir las diferentes pautas productivas de los dos principales núcleos de las colonias del oeste santafesino, vale la pena echar luz sobre algunos indicadores puntuales del proceso de acumulación. Se busca analizar la evolución de los componentes de la inversión en las dos principales colonias en las décadas de 1860 y 1870 y compararlos al mismo tiempo con las colonias satélites surgidas bajo su seno.

La gráfica 1 pretende mostrar por lo menos dos cuestiones de marcada importancia. Por una parte, vuelve a dar cuenta de las diferencias en los patrones de producción entre ambas colonias, teniendo así los agricultores de San Carlos una importancia mucho mayor que los de Esperanza. Esto es, $84 \%$ del total de la riqueza inmobiliaria sancarlina estaba en manos de los agricultores, mientras que en Esperanza esta proporción se reduce a la mitad. Las razones ya remarcadas de estas diferencias apuntaban principalmente a las limitaciones de Esperanza para expandir su extensión y a un mejor planeamiento de las pautas productivas en San Carlos.

Sin embargo, vale destacar otra cuestión de interés; si bien el crecimiento del comercio o de los oficios semiindustriales -a lo que nos referiremos más adelante- fue relativamente alto en Esperanza, de todos modos la mitad de la riqueza en la colonia continuaba estando en poder de los agricultores. Por ende, este hecho permite poner en duda -al menos hacia fines de la década de 1860- algunas visiones tradicionales que apuntaban al pauperismo de los productores a causa del accionar monopólico de otros sectores, relacionados con el comercio y las finanzas, sobre el productivo. $^{29}$

Esta situación, no obstante, cambiaría en Esperanza -y no en San Carlos- para mediados de la década de 1870, lo cual redundaría, como se vio en el apartado anterior, en un mayor aumento de la desigualdad a causa de esa modificación en los rubros de acumulación de riqueza. Para 1875, en Esperanza los agricultores perderían terreno principalmente frente a los molineros, los emprendimientos semiindustriales y en menor medida frente a los comerciantes, actividades que lógicamente, al menos en sistemas de producción minifundistas, tendían a una mayor concentración de capital que las actividades agrícolas. Ahora bien, ¿̇ué pasaba en las nuevas colonias? La gráfica 2 -que mide la distribución de la riqueza inmobiliaria

${ }^{29}$ Véase, entre otros, Scobie, Revolución, 1968. Esta visión también tuvo vigencia en los análisis de la colonización brasileña, véase Seyferth, Colonização, 1974. 


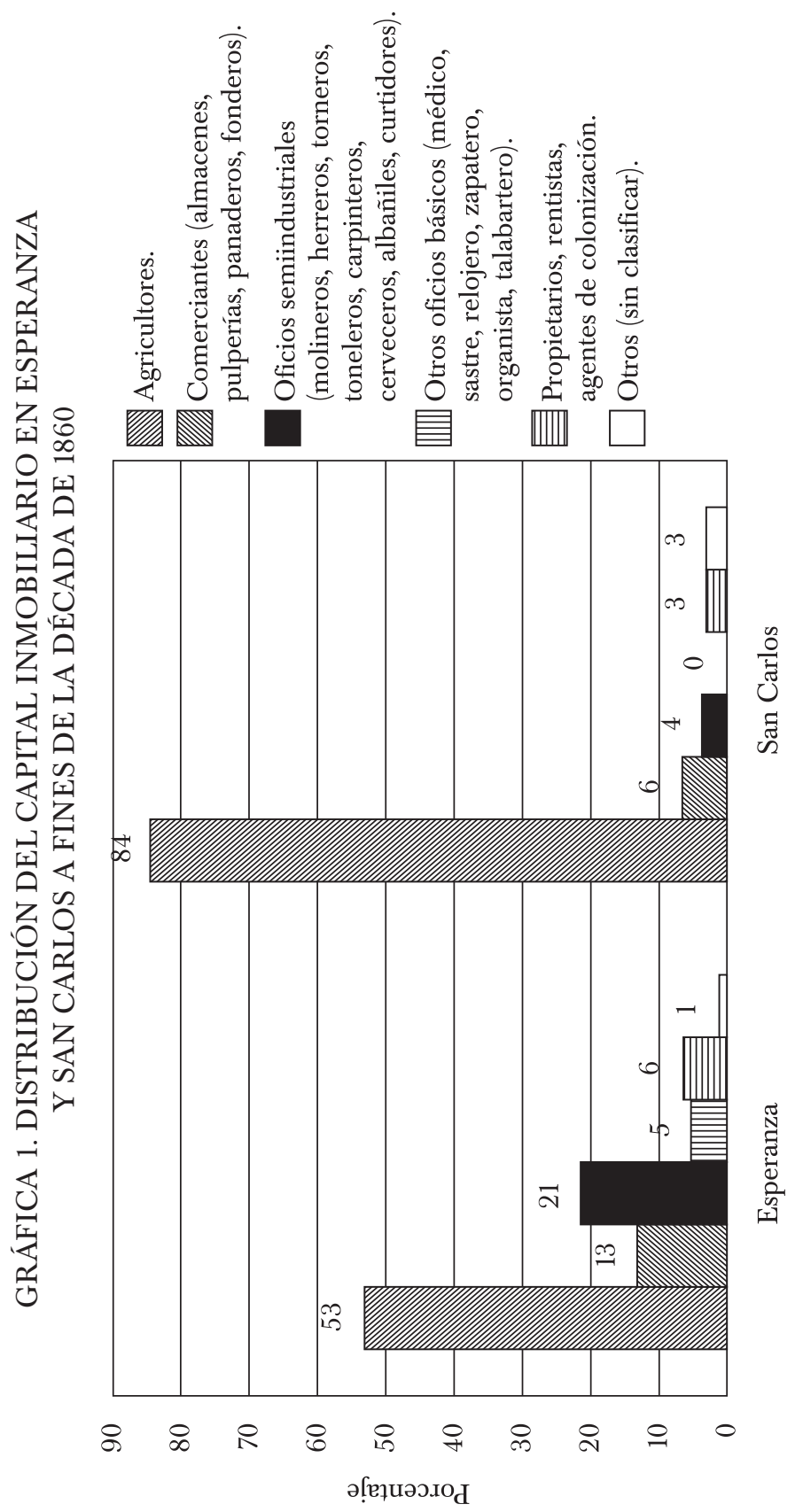

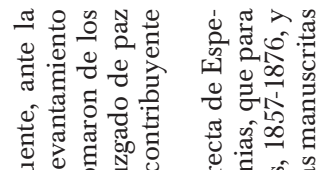

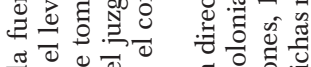

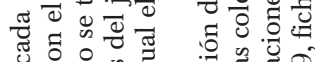
ن 0 :

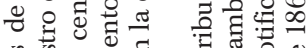
ข ¿

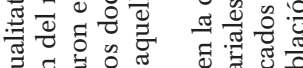

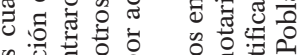
की

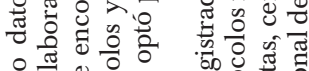

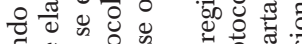

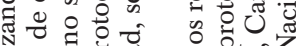

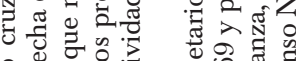

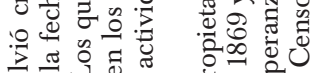

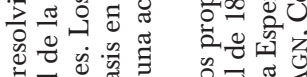

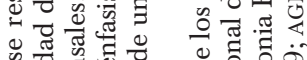

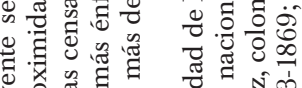

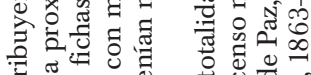

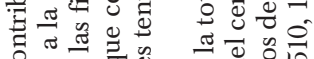
ช் \&

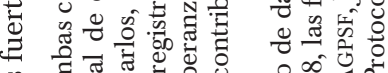

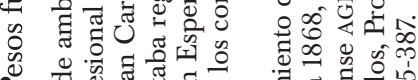

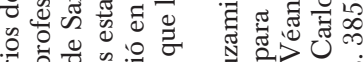

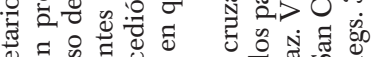

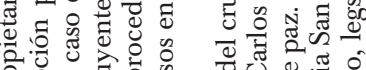

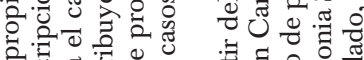

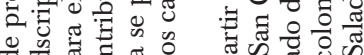
\& 劳

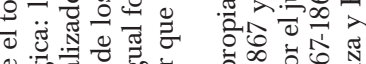

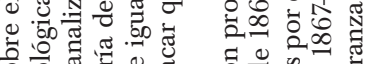

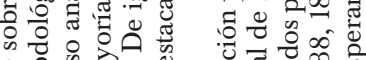

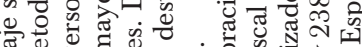

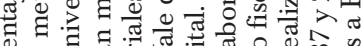

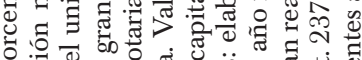

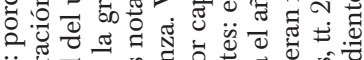

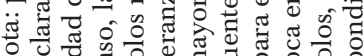

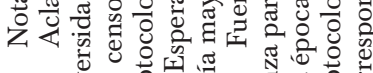

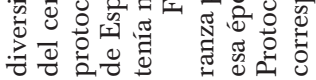




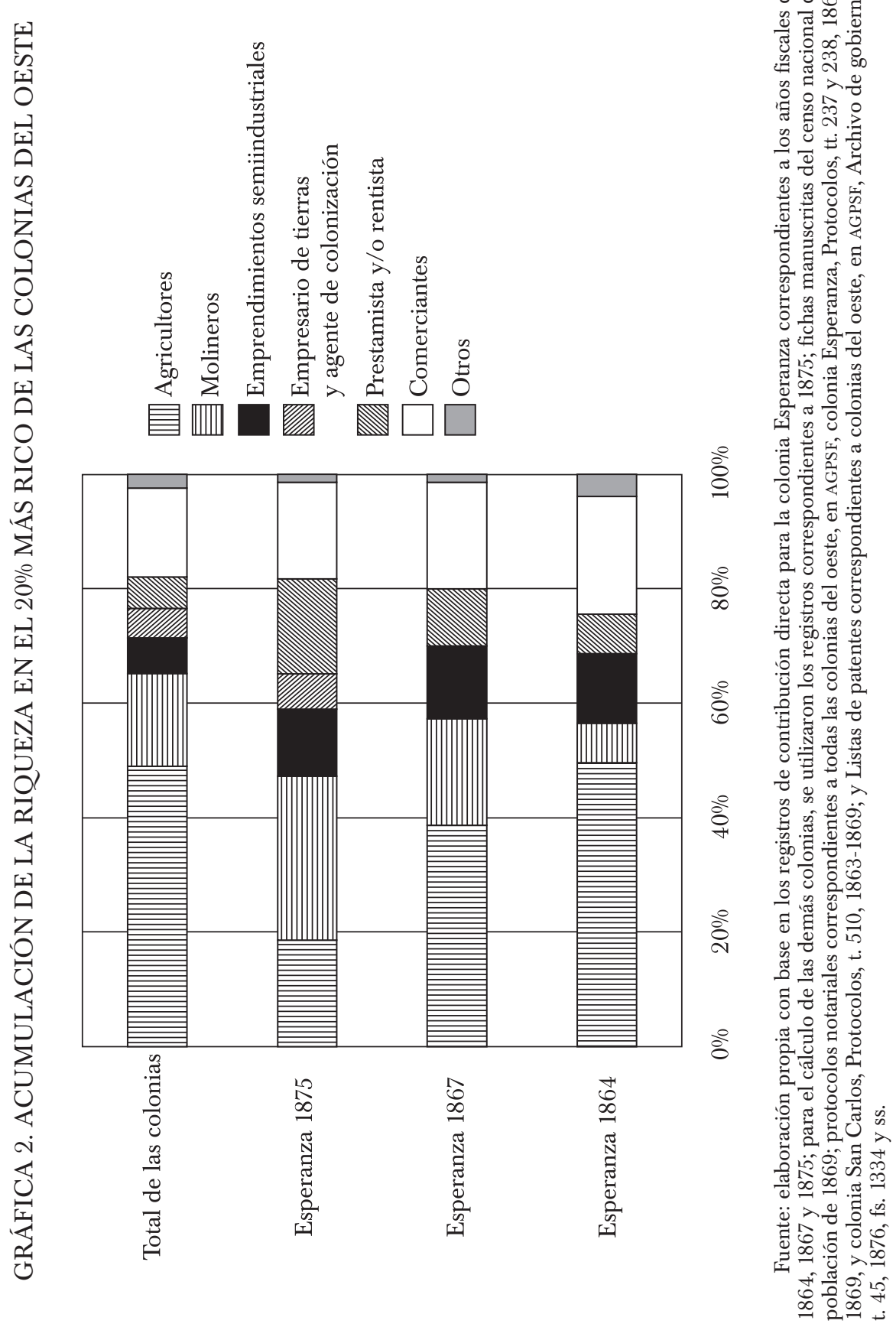


en los dos deciles más altos a lo largo de dos décadas para Esperanza y puntualmente de 1875 para el total de las colonias- permite realizar una serie de interpretaciones en este sentido.

Si bien, a diferencia de la gráfica 1 que toma el universo total de contribuyentes, en la gráfica 2 se analiza sólo al sector más rico de la población, entendemos que los resultados obtenidos son válidos para mostrar los componentes de inversión de ese segmento, ya que los dos deciles más altos del universo total de contribuyentes concentraban $51.4 \%$ de la riqueza inmobiliaria total de las colonias del centro oeste. ${ }^{30}$ En consecuencia, es importante destacar, por un lado, la sensible declinación de la agricultura esperancina y el fuerte crecimiento de otros sectores asociados a la producción de valor agregado. Dentro del rubro de emprendimientos semiindustriales incluimos a las atahonas -generalmente con capital considerable, aún continuaban siendo importantes en la molienda del trigo pese al crecimiento de los molinos a vapor-, las herrerías -de gran importancia en la fabricación o reparación de instrumentos agrícolas-, los carpinteros - principalmente aquellos que se encargaban de la fabricación de carros de transporte de cereales-, horneros -fabricantes de ladrillos- y otros oficios de menor envergadura, como toneleros, cerveceros, curtidores, constructores, entre otros. En mayor medida las atahonas, los herreros y los carpinteros fueron los sectores que empujaron el incremento de la riqueza inmobiliaria de este rubro; vale destacar, por ejemplo, el caso de Luis Tabernig, en cuya herrería, tasada en 5000 pesos fuertes en el registro de contribución directa de 1875, se fabricaban arados y otros instrumentos agrícolas de gran renombre en el ámbito de las colonias. El rubro de prestamistas y/o rentistas incluye a aquellos contribuyentes que eran dueños de solares o construcciones urbanas y también a aquellos cuya actividad principal consistía principalmente en préstamos hipotecarios. Este aumento se debe mayormente a la gran expansión que para 1875 había experimentado el núcleo urbano de Esperanza, con una valorización muy importante de sus activos. Y por último, debe remarcarse el caso de los molineros, el rubro más concentrado y de mayor crecimiento en el periodo. Más allá de la alta proporción que ocupa en el total del capital del grupo más rico, lo interesante es remarcar las razones de su crecimiento.

\footnotetext{
${ }^{30}$ Para el análisis de todas las colonias en 1875 se tomó en consideración sólo el 20\% más rico de todos los contribuyentes de las colonias del oeste santafesino (esto es, 20\% sobre un total de 1116 colonos), debido a que resulta imposible detectar la adscripción profesional de todos los contribuyentes de ese año. Contrariamente al análisis realizado sobre los 409 contribuyentes de Esperanza y San Carlos en 1867 y 1868 (véase gráfica 1), para el cual contamos con el censo de 1869 y los protocolos, no existía en 1875 un censo próximo y a ello se sumaba la existencia de una importante masa de nuevos colonos que resultan más difíciles de ubicar en las fuentes.
} 
Para 1875, y pese a los efectos de la crisis de 1873, la evolución de la estructura socioeconómica del hinterland colonial había tenido un crecimiento muy importante. El aumento de la producción agrícola al calor de la puesta en producción de las colonias satélites había sentado las bases de una economía que, aunque todavía se encontraba en una etapa exportadora en ciernes, transformaba a la industria molinera en un engranaje fundamental de su estructura, no sólo por la producción de valor agregado a las materias primas, sino también porque alimentaba el funcionamiento de los circuitos comerciales y del mercado de tierras. ${ }^{31}$

Por otra parte, el sector más rico en la totalidad de las colonias admitía, como podía preverse, otra composición de sus inversiones, con un predominio importante de los agricultores, que ostentaban la mitad de la riqueza inmobiliaria de ese grupo en las nueve colonias en estudio. La explicación parece bastante lógica: el éxito agrícola de San Carlos se había replicado en Franck y San Agustín, ${ }^{32}$ y buena parte de los agricultores de Esperanza y San Gerónimo también habían volcado sus inversiones en tierras hacia Cavour, Humboldt, Santa María, por un lado, y Las Tunas, por otro. ${ }^{33}$ Los otros sectores en importancia, molineros y comerciantes, estaban lógicamente concentrados en Esperanza y San Carlos (78\% del total del capital que concentraban los comerciantes del grupo más rico era oriundo de estas dos colonias, y en el rubro de molinería, alcanzaban 90\%). Finalmente, el resto de los rubros parece haber tenido una composición similar a la de Esperanza, a excepción de los prestamistas y/o rentistas, que al tener una impronta más urbana, se concentraban puntualmente en Esperanza. ${ }^{34}$

En fin, más allá del giro comercial y semiindustrial de Esperanza, el mapa de la distribución de la riqueza a mediados de la década de 1870 muestra claramente que la agricultura era el centro principal de la generación de ganancias que se volcaban en inversiones inmobiliarias y la pieza fundamental de la economía del hinterland colonial.

\footnotetext{
${ }^{31}$ En este sentido, arriesgamos la hipótesis de que ante la escasez de circulante por la falta de instituciones bancarias, no sólo el crédito hipotecario fue fundamental en el desarrollo del mercado de tierras en las colonias, sino también la industria molinera, ya que los vales de pago por acopio de semillas parecen haber sido ampliamente utilizados como moneda corriente.

${ }^{32}$ Vale destacar que el rubro de agricultores del grupo más rico del total de las colonias concentraba una riqueza total de 296925 pesos fuertes. De esa cifra, 73\% correspondía a colonos de San Carlos, San Agustín y Franck.

${ }^{33}$ Además de los agricultores de las colonias primigenias que directamente se instalaron en las nuevas colonias, haciendo de estas su base de operaciones, vale destacar que en $1875,10 \%$ de la riqueza inmobiliaria de agricultores que no se habían mudado de las colonias primigenias, se encontraba invertido en las colonias satélites.

${ }^{34} 83 \%$ del capital del rubro de prestamistas y/o rentistas del grupo más rico en 1875 estaba concentrado en Esperanza.
} 


\section{CONSIDERACIONES FINALES}

Ha sido ampliamente trabajado el éxito relativo que ha tenido el proceso de colonización agrícola en la transformación de la provincia de Santa Fe durante la segunda mitad del siglo XIX. Existe un extenso consenso historiográfico que además de destacar los indudables avances macroeconómicos y productivos de este proceso, ha matizado las visiones tradicionales sobre las condiciones de vida de los agricultores. Ahora bien, queda mucho por indagar acerca de otros aspectos no menos importantes, como es el caso de la distribución y los componentes de la riqueza inmobiliaria.

A esta altura parece indudable pensar que los contrastes con la economía criolla no sólo se daban en el plano productivo, sino también en la distribución. Es bien sabido que las explotaciones agrarias de Esperanza y San Carlos poseían una mayor inversión de capital por unidad que los módulos productivos típicos de la economía ganadera criolla, lo cual redundaba en el mayor dinamismo de su economía agraria. Por otro lado, el rendimiento del trabajo era mucho mayor, en la medida en que se trataba de rubros más intensivos. Sólo hacía falta encontrar mercados aptos para absorber esa ampliación de la oferta de bienes agrícolas, lo cual se logró primero con la demanda generada por los ejércitos en lucha en Paraguay, y luego con la provisión a las ciudades litorales y por fin al mercado mundial. Sin embargo, ce ello constituía un factor que diera impulso a una distribución más homogénea de la riqueza? En principio, aunque de manera muy preliminar, podríamos afirmar que sí, por el simple hecho de que en los casos analizados todos los indicadores estadísticos registran que ese marcado contraste inicialmente en la distribución de la riqueza respecto a la producción criolla logra, de una u otra forma, mantenerse en el tiempo, aun a pesar de ciertos aumentos en los índices de desigualdad. Sin embargo, deben advertirse algunas cuestiones importantes. Si bien es cierto que las áreas de producción en ambos casos constituían en sus primeros años espacios relativamente homogéneos, en ambos desempeñó un papel central la existencia de una frontera abierta. En Esperanza, parece quedar claro que muchos colonos que no habían podido sortear los obstáculos que afectaron la eficiencia productiva de la colonia, tuvieron que buscar oportunidades en tierras más alejadas. Ello por ende contribuyó, al menos en un primer momento, a "homogeneizar" el universo de propietarios y en cierto sentido a morigerar la desigualdad. En San Carlos, el efecto de la frontera fue inverso, ya que la configuración espacial de la colonia permitió la absorción de nuevos flujos de población al mismo tiempo que contribuyó a mantener bajo el precio de la tierra y alta su productividad. La puesta en producción de nuevas tierras permitió un crecimiento fenomenal de la riqueza que redundó sin duda en un crecimiento de la desigualdad en la década siguiente. 
El resumen de la década de 1860 parece arrojar entonces una relativa estabilidad en la distribución de la riqueza que, como vimos, se verá en buena medida afectada en la década siguiente. Se matizaría así el posible papel de procesos de convergencia con la economía circundante criolla, o de la sola dinámica de la acumulación como factores que hubieran tendido a cerrar esa brecha inicial entre ambas economías en lo que respecta a la desigualdad. En suma, más allá de la distribución de factores propia de esa lógica productiva, la explicación a esta desigual distribución parece estar en aspectos coyunturales y a la vez estructurales. Si es cierto que el proceso de acumulación en el periodo fue espectacular, también lo es que parte del mismo fue debido al surgimiento de un factor en cierto modo externo al proceso en sí, esto es, la emergencia de un sector urbano en el seno mismo del área de colonización. Probablemente sea esa quizá la principal variable explicativa del aumento de la desigualdad en Esperanza y San Carlos a mediados de la década, en tanto importó aumentos muy rápidos del valor de la hectárea ligados al surgimiento de industrias procesadoras y áreas de servicios con índices más altos de densidad poblacional, sin que hubiera tiempo aún para que se manifestaran procesos de fragmentación, cosa que ocurrirá más adelante.

Ahora bien, más allá de cuánto se acumuló y de cómo se distribuyó esa riqueza inmobiliaria, otro de los objetivos fue indagar quiénes acumularon y por qué. En este sentido se pudo ver de qué manera la estructura productiva y geográfica de cada colonia pareció determinar la lógica económica de sus actores. Así podemos saber que esa dimensión urbana que emergió en Esperanza no sólo hizo eco en la distribución de la riqueza, sino que también se tradujo en una modificación de los actores productivos. Ello implicó un importante crecimiento de emprendimientos semiindustriales, o bien, de actividades comerciales, en detrimento de los agricultores, que modificaron sus pautas de inversión o buscaron colocar sus excedentes en colonias aledañas. Tanto Esperanza con su impronta "urbana" como San Carlos con su predominio agrícola, contagiaron de alguna manera los patrones de producción de las colonias satélites. Para concluir, esto permite pensar que, pese al tremendo crecimiento de algunas actividades ligadas a la producción de valor agregado a las materias primas, todavía para mediados de la década de 1870, la preponderancia de los agricultores estaba lejos de ser cuestionada. 


\section{FuENTES CONSULTADAS}

\section{Archivos}

AGN Archivo General de la Nación, Argentina.

AGPSF Archivo General de la Provincia de Santa Fe.

AMM Archivo Museo Mitre.

\section{Bibliografía}

Acemoglu, Daron, Simon Johnson y James Robinson, "Institutions as the Fundamental Cause of Long-Run Growth" en Philippe Aghion y Steven N. Durlauf (eds.), Handbook of Economic Growth, Amsterdam, North Holland, 2005.

Beck Bernard, Charles, La République Argentine. Manuel de l'émigrant et du cultivateur, Berne, Imprimerie J. Allemann, 1872.

BÉRTOLA, LuIS, Ensayos de historia económica: Uruguay y la región en la economía mundial 1870-1990, Montevideo, Trilce, 2000.

"A cincuenta años de la curva de Kuznets. Crecimiento económico y distribución del ingreso en Uruguay y otras economías de nuevo asentamiento desde 1870", Investigaciones de Historia Económica, Asociación Española de Historia Económica/Universidad Complutense de Madrid, núm. 3, 2005.

Bonaudo, Marta y Elida O. Sonzogni, "Cuando disciplinar fue ocupar (Santa Fe, 1850-1890)", Mundo Agrario. Revista de Estudios Rurales, Universidad Nacional de La Plata, núm. 1, 2do. semestre de 2000, La Plata.

CÁrcano, Miguel A., Evolución histórica del régimen de la tierra pública, 1810-1916, Buenos Aires, EudebA, 3a. ed., 1972.

Coelho, Guillermo, Memoria presentada al excmo. gobierno de la provincia de Santa Fe por el inspector de colonias, Buenos Aires, Imp. a Vapor de Juan H. Kidd y Cía., 1875.

Cortés Conde, Roberto, El progreso argentino. 1880-1914, Buenos Aires, Sudamericana, 1979.

DJENDEREDJIAN, Julio CÉSAR, "La colonización agrícola en Argentina, 1850-1900: problemas y desafíos de un complejo proceso de cambio productivo en Santa Fe y Entre Ríos", América Latina en la Historia Económica, Instituto de Investigaciones Dr. José María Luis Mora, núm. 30, julio-diciembre de 2008, México.

y JuAn Luis MARTiRÉn, "Economía rural criolla y colonización en la década de 1860. Análisis de estructuras poblacionales y distribución de la riqueza rural en Esperanza, Santa Fe, y Paraná, Entre Ríos” en XJornadas Argentinas de Estudios de Población, Catamarca, Universidad Nacional de Catamarca, noviembre de 2009.

Djenderedjian, Julio CéSAR y Robert Schmit, "Sombras detrás de un discreto crecimiento económico. La distribución de la riqueza en Entre Ríos, 1860-1880”, Red de Estudios Rurales, Instituto Ravignani, diciembre de 2005. 
Engerman, Stanley L. y Kenneth L. Socoloff, "Dotaciones de factores, instituciones y vías de crecimiento diferentes entre las economías del nuevo mundo. Una visión de historiadores de economía estadounidenses" en STEPHEN HABER (comp.), Cómo se rezagó la América Latina. Ensayos sobre las historias económicas de Brasil y México, México, Fondo de Cultura Económica, 1999.

FrID, CARINA, "Preludio a la pampa gringa", trabajo presentado en la Red de Estudios Rurales, Instituto Ravignani, abril de 2007.

Gallo, Ezequiel, "Santa Fe en la segunda mitad del siglo XIX. Transformaciones en su estructura regional”, Anuario del Instituto de Investigaciones Históricas, Universidad Nacional del Litoral, núm. 7, 1965, Rosario.

"Agricultural Colonization and Society in Argentina. The Province of Santa Fe (1870-1895)", tesis de doctorado en Filosofía, Oxford, University of Oxford, 1970.

Gelman, Jorge y Daniel Santilli, De Rivadavia a Rosas. Desigualdad y crecimiento económico, t. III: Historia del capitalismo agrario pampeano, Buenos Aires, Siglo XXI/ Universidad de Belgrano, 2006.

"Una creciente desigualdad. La propiedad de la tierra en Buenos Aires entre 1839 y 1855", ponencia presentada en el XXVIII International Congress of the Latin American Studies Association, Rio de Janeiro, 2009.

Gobierno Nacional de Argentina, Die Argentinische Republik, Berna, Buchdruckerei von J. Alemann, 1869.

Kuznets, Simon, Modern Economic Growth, New Haven, Yale University Press, 1966.

Martirén, JuAn Luis, "Colonias agrícolas y mercado de tierras en el centro oeste de la provincia de Santa Fe. Los casos de Esperanza y San Carlos (1856-1875)", ponencia presentada en las XXII Jornadas de Historia Económica, Asociación Argentina de Historia Económica, Río Cuarto, Universidad Nacional de Río Cuarto, septiembre de 2010.

Oddone, Jacinto, La burguesía terrateniente argentina, Buenos Aires, Libera, 1967.

Ortiz, Ricardo M., Historia económica de la Argentina, Buenos Aires, Raigal, 1955.

Randle, Patricio H., Atlas del desarrollo territorial de la Argentina, Buenos Aires, Oikos, 1981.

Scobie, James, Revolución en las pampas. Historia social del trigo argentino, 1860-1910, Buenos Aires, Solar/Hachette, 1968.

SEyferth, Giralda, A colonização alemã no vale do Itajaí-Mirim. Um estudo de desenvolvimento econômico, Porto Alegre, Editora Movimento/Sociedade Amigos de Brusque, 1974.

Wilcken, Guillermo, Las colonias. Informe sobre el estado actual de las colonias agrícolas de la república argentina presentado a la Comisión Central de Inmigración por el inspector nacional de colonias, Buenos Aires, Sociedad Anónima, 1873.

Williamson, JefFrey G., "Real Wages, Inequality and Globalization in Latin America before 1940", Revista de Historia Económica. Journal of Iberian and Latin American Economic History, Instituto Figuerola de Historia Económica, Universidad Carlos III de Madrid, año 17, núm. extra 1, 1999, pp. 101-142.

y Peter H. Lindert, American Inequality. A Macroeconomic History, Nueva York, Academic Press, 1980. 